\title{
Potential objectives for gibberellic acid and paclobutrazol under salt stress in sweet sorghum (Sorghum bicolor [L.] Moench cv. Sofra)
}

\author{
Amir Hossein Forghani ${ }^{1} \cdot$ Abbas Almodares $^{1} \cdot$ \\ Ali Akbar Ehsanpour ${ }^{1}$
}

Received: 27 August 2017/Accepted: 7 November 2017/Published online: 31 January 2018

(C) The Korean Society for Applied Biological Chemistry 2018

\begin{abstract}
The phytohormones are important in plant adaptation to abiotic and biotic stresses by facilitating a wide range of adaptive responses. Application of gibberellic acid $\left(\mathrm{GA}_{3}\right)$ and paclobutrazol $(\mathrm{PBZ})$ as $\mathrm{GA}_{3}$ inhibitors have been shown to affect salinity tolerance through modulating phytohormones. The aim of this study was to find out the potential objectives for $\mathrm{GA}_{3}$ and PBZ as affected by salinity through altering the phytohormones and biochemical parameters in sweet sorghum. Following seed germination, seedlings were cultured in Hoagland nutrient solution containing $\mathrm{NaCl}$ supplemented with $\mathrm{GA}_{3}$ and PBZ for 12 days. The results were analyzed by principal component analysis to identify the best target(s) for salinity, $\mathrm{GA}_{3}$, and PBZ in sweet sorghum. Paclobutrazol associated with salt improved root/shoot length, carotenoid, and total chlorophyll by modulating cytokinin $(\mathrm{CK}) / \mathrm{GA}_{3}$, indole acetic acid (IAA) $/ \mathrm{GA}_{3}$, and total polyamines $/ \mathrm{GA}_{3}$ ratios. Gibberellic acid-treated plants not exposed to salinity treatments notably improved phytohormones content such as cytokinin, auxin, abscisic acid (ABA), and polyamines resulting in increased stem growth. Moreover, the main objectives of $\mathrm{GA}_{3}$ were $\mathrm{ABA}$, spermidine, and $\mathrm{ABA} / \mathrm{GA}_{3}$ ratio in response to salinity. Though $\mathrm{GA}_{3}$ and $\mathrm{PBZ}$ have different roles against salt stress, $\mathrm{ABA} /$ $\mathrm{GA}_{3}$ ratio was a similar target of $\mathrm{GA}_{3}$ and PBZ. This work suggests that altered levels of $\mathrm{GA}_{3}$ resulting from PBZ- and $\mathrm{GA}_{3}$-treated plants cause different allocation patterns in sweet sorghum by regulation of $\mathrm{CK} / \mathrm{GA}_{3}, \mathrm{IAA} / \mathrm{GA}_{3}$, and total polyamines/GA $\mathrm{GA}_{3}$ ratio. Also, accumulation chlorophyll pigments, carotenoids, and water soluble
\end{abstract}

Ali Akbar Ehsanpour

ehsanpou@sci.ui.ac.ir

1 Department of Biology, University of Isfahan, Isfahan, Iran carbohydrates of sorghum plants under salinity regulated by total polyamines/GA 3 and $\mathrm{ABA} / \mathrm{GA}_{3}$ ratios positively correlated with PBZ application.

Keywords Auxin · Chlorophyll · Cytokinin · Hormone cross-talk $\cdot$ Polyamines

\section{Introduction}

Salinity is a major problem in agriculture and crop production. High concentration of toxic ions creates salty soil regions around the world. Sodium and chloride are main ions in most of the salty areas, and $\mathrm{NaCl}$ is the most damaging compound for plant growth and development. The negative effects of salinity on plant growth and leaf senescence are related to osmotic stress and ion toxicity [1-3].

Sweet sorghum (Sorghum bicolor) has usually been grown in areas with relatively low rainfall, high temperatures, and saline soils. This plant, as a moderately salt tolerant crop, has been adapted to water limitation and is more tolerant to salinity at germination stage than in the later stages of growth [4, 5]. Moreover, sorghum is an important food and bioenergy source as well as a model plant for studying the mechanisms of drought and salt tolerance in cereals [3, 6]. A number of methods have been developed for screening salt tolerance in plants because majority of physiological processes (e.g., germination, photosynthesis, biomass production, and chlorophyll content) are highly sensitive to salt stress [3]. Plants can adjust their growth and development in response to salt stress by signaling molecules. Phytohormones are active members of signal cascade involved in the induction of salt stress responses [7]. Several phytohormones such as abscisic acid 
(ABA), cytokinin (CK), auxin (Aux), polyamines, and gibberellic acid $\left(\mathrm{GA}_{3}\right)$ have been used to reduce the negative effects of salt stress on seed germination, plant growth, and fruit setting [8]. Recently, $\mathrm{GA}_{3}$ has been considered as a growth regulator to ameliorate salt stress. This hormone has been used to increase wheat and rice growth under salinity condition [8]. The function of phytohormones is complicated due to their interactions with other plant growth regulators. In case of $\mathrm{GA}_{3}$ action, no specific target of GA-induced genes has been identified which may propose interaction with other hormones plays a key role in response to stress [7]. How gibberellins treatment may induce salt tolerance in plants has not been clearly answered yet [9]. It has been shown that $\mathrm{GA}_{3}$ and ABA play antagonistic roles in many plants' developmental processes such as germination, growth, and flowering. Moreover, the antagonistic effects of $\mathrm{GA}_{3}$ and $\mathrm{CK}$ on some growth parameters have been previously reported [7]. In contrast, it has been indicated that $\mathrm{GA}_{3}$ and auxin frequently act synergistically, especially in stem elongation [7]. Recently, it was reported that auxin is positively associated with $\mathrm{GA}_{3}$ by promoting degradation of DELLA protein [7]. It has also been known that, salt stress reduces endogenous cytokinins and improves ABA and polyamines levels [7], especially spermine in sorghum [10]. Studies have shown that polyamines have positive effects in plants facing environmental stresses [10]. Although polyamines are essential for cell division and root initiation [10], little is known about signal transduction of polyamines and their interaction with $\mathrm{GA}_{3}$. Triazoles such as paclobutrazol (PBZ) affect the isoprenoid pathway and alter the levels of certain plant hormones by inhibiting gibberellin synthesis, reducing ethylene evolution and increasing $\mathrm{CK}$ and $\mathrm{ABA}$ levels [11]. Triazole compounds also protect plants against various stresses, and they have been characterized as plant multi-protectants [12]. Application of PBZ has been reported to mitigate salt stress in some plant species by reducing the level of $\mathrm{GA}_{3}$ via inhibition of monooxygenases which catalyze oxidative steps from ent-kaurene to ent-kaurenoic [13]. However, the actual mechanism of stress tolerance by PBZ remains unclear. It seems $\mathrm{GA}_{3}$ and PBZ may increase salt tolerance by different mechanisms and they may have different physiological, biochemical, and hormonal objectives. To the best of our knowledge, no comparative study has been reported in plants using $\mathrm{GA}_{3}$ and PBZ under salt stress. In the current study, we aim to understand: (1) How $\mathrm{GA}_{3}$ and its inhibitor (PBZ) interact with other plant hormones under salt stress conditions; and (2) among carbohydrates, photosynthetic pigments, polyamines, and phytohormones, what are the best objectives for $\mathrm{GA}_{3}$ and $\mathrm{PBZ}$ to ameliorate the negative effects of salt stress in sweet sorghum as a model plant.

\section{Materials and methods}

\section{Hydroponic culture}

Fresh seeds of sweet sorghum (Sorghum bicolor [L.] Moench cv. Sofra) were supplied from the seed stock University of Isfahan, Iran. Seeds were surface sterilized for 1-2 min in $95 \%$ ethanol, followed by $15 \%$ sodium hypochlorite $(\mathrm{v} / \mathrm{v})$ for $20 \mathrm{~min}$. Seeds were then washed three times using sterilized distilled water and transferred into the plastic pots containing sterile perlite and watered with Hoagland nutrient solution. Pots were then kept in the culture room at $25 \pm 1{ }^{\circ} \mathrm{C}$ with $16 / 8 \mathrm{~h}$ photoperiod under $100 \mu \mathrm{mol} \mathrm{m} \mathrm{m}^{-2} \mathrm{~s}^{-1}$ light intensity derived from white fluorescent lamps. After germination, five seedlings were transferred to the new pots and each pot was moved inside a $200 \mathrm{~mL}$ container filled with Hoagland nutrient solution [14]. After 4 days, the nutrient solution of pots was replaced by fresh Hoagland medium containing 0, 100, 150,200 , and $250 \mathrm{mM} \mathrm{NaCl}$, supplemented with either PBZ $(17 \mu \mathrm{M})$ or $\mathrm{GA}_{3}(17 \mu \mathrm{M})$. Pots with neither salt nor PBZ or $\mathrm{GA}_{3}$ were used as control. After 12 days, treated plants were harvested and their biochemical and physiological parameters were measured as described below.

\section{Growth parameters}

A number of leaves, stem and root lengths as well as fresh weight (FW) of plants were measured after 12 days. To determine the dry weight, samples were dried in a $70{ }^{\circ} \mathrm{C}$ oven for $48 \mathrm{~h}$. Shoot water content was measured by calculating the difference between the fresh and dry weights of the plants.

\section{Photosynthetic pigments}

For photosynthetic pigments' measurements, leaves $(0.1 \mathrm{~g}$ FW) of plants were ground in $80 \%$ cold acetone and centrifuged at $5000 \mathrm{~g}$ for $10 \mathrm{~min}$. The absorbance of the purified chlorophyll samples was measured at 470, 646, and $663 \mathrm{~nm}$ (Shimadzu UV-160, Kyoto, Japan). Chlorophyll and carotenoid contents were calculated according to Lichtenthaler and Wellburn [15].

\section{Carbohydrate content}

Water soluble carbohydrates (WSC) were determined based on the phenol-sulfuric acid method described by Dubois et al. [16]. To prepare carbohydrate extract, $10 \mathrm{mg}$ of dry leaf was homogenized with $10 \mathrm{~mL} 80 \%$ ethanol. The extracts were centrifuged at $6000 \mathrm{rpm}$, and $0.5 \mathrm{~mL}$ of supernatant was mixed with $0.5 \mathrm{~mL}$ of $5 \%$ phenol and 
$2.5 \mathrm{~mL} 96 \%$ sulfuric acid. The samples were then vortexed gently for $30 \mathrm{~min}$, and soluble carbohydrates were measured at $490 \mathrm{~nm}$.

\section{Measurement of phytohormones using HPLC}

The level of indole acetic acid, cytokinin, and gibberellic acid was determined by method described below. Extraction: Approximately $2 \mathrm{~g}$ of tissue was ground in $30 \mathrm{~mL}$ cold $80 \%$ methanol and homogenized in darkness at $4{ }^{\circ} \mathrm{C}$, then centrifuged at $5000 \mathrm{rpm}$ at $4{ }^{\circ} \mathrm{C}$ for $15 \mathrm{~min}$. The supernatant was filtered through $0.45 \mu \mathrm{m}$ Whatman $^{\mathrm{TM}}$ filter to remove suspended particles [17-19]. The filtered supernatant was treated sequentially with methanol-acetic acid (100:1, v/v), methanol-water-acetic acid (50:50:1, $\mathrm{v} / \mathrm{v} / \mathrm{v})$, methanol-water-acetic acid (30:70:1, v/v/v), and finally with water before transferring $100 \mathrm{~mL}$ of filtrate to 10 C18 SPE columns (J.T. Baker, Phillipsburg, NJ, USA; $500 \mathrm{mg}, 3 \mathrm{~mL}$ ). The columns were washed with $10 \mathrm{~mL}$ water adjusted to $\mathrm{pH} 3$ with acetic acid (acidified water). The phytohormones were eluted with $5 \mathrm{~mL}$ ethanol-wateracetic acid (80:20:1, v/v/v). The eluate was evaporated at room temperature under vacuum and finally, the evaporated eluate was dissolved in $1 \mathrm{~mL}$ methanol [17]. Prior to HPLC analysis, this reconstituted eluate was filtered using a $0.45 \mu \mathrm{m}$ Whatman ${ }^{\mathrm{TM}}$ glass microfiber filter.

Evaluation by HPLC: Analysis of phytohormones was performed based on Ge et al. [20] and Ma et al. [17], using a HPLC system (Unicam, Crystal 200, Cambridgeshire, England) linked simultaneously to a photodiode array (PDA) system. Ten $\mu \mathrm{L}$ of extract was injected into a $\mathrm{C} 18$ reverse phase column (Zorbax SB-C18 100A ${ }^{\circ}, 3.5 \mu \mathrm{m}$, $150 \mathrm{~mm}$ length, $2.1 \mathrm{~mm}$ diameter). The column thermostat was set at $25{ }^{\circ} \mathrm{C}$. The initial HPLC column running conditions was initialized isocratically with methanol-formic acid buffer (10:90, v/v) for $5 \mathrm{~min}$, then a linear gradient to methanol-formic acid buffer (30:70, v/v) in $5 \mathrm{~min}$, which was later maintained isocratically for $10 \mathrm{~min}$, before switching to a linear gradient toward a methanol-formic acid buffer $(45: 55, \mathrm{v} / \mathrm{v})$ in $35 \mathrm{~min}$ and finally isocratically at methanol-formic acid buffer (45:55, v/v) for $15 \mathrm{~min}$. Under the separation conditions, all compounds were successfully separated within $45 \mathrm{~min}$. After each analysis, the column was washed with 95:5 methanol-formic acid buffer for $5 \mathrm{~min}$. Then formic acid buffer-methanol 90:10 for $30 \mathrm{~min}$ was used to re-equilibrate. The peak area of the standard was considered for determination of sample concentration. Quantification of phytohormones was calculated based on Ge et al. [20], Ma et al. [17], and Tang et al. [19] methods using the peak areas with identified amounts of IAA, CK, and GA3.

For extraction and evaluation of ABA, $1 \mathrm{~g}$ of fresh leaves were ground in $10 \mathrm{~mL}$ of $80 \%$ methanol including
$0.01 \mathrm{~g}$ of ascorbic acid and $0.01 \mathrm{~g}$ polyvinylpyrrolidone (PVP). The homogenate was stirred overnight at $4{ }^{\circ} \mathrm{C}$. After centrifugation at $4000 \mathrm{~g}$ for $15 \mathrm{~min}$, the supernatant was recovered and adjusted to $\mathrm{pH}$ 8.0. The aqueous methanol was evaporated under reduced pressure at $35^{\circ} \mathrm{C}$. The residue was dissolved in $5 \mathrm{~mL}$ of water. These samples were frozen and thawed for three cycles. After centrifugation at $4000 \mathrm{~g}$ for $15 \mathrm{~min}$, the supernatant was recovered and adjusted to $\mathrm{pH} 2.5$ and $10 \mathrm{~mL}$ ethyl acetate was added to collect free ABA in ethyl acetate. The ethyl acetate was then evaporated. The resulting dried precipitate was dissolved in $1 \mathrm{~mL}$ of $3 \%$ methanol containing $0.1 \mathrm{M}$ acetic acid and was filtered through a $0.45 \mathrm{~mm}$ membrane filter [21]. Then, $10 \mu \mathrm{L}$ of extract was injected into a $\mathrm{C} 18$ reverse phase column $(4.6 \times 250 \mathrm{~mm}$ Diamonsic C18, $5 \mu \mathrm{m})$. It was eluted with a linear gradient of methanol (3-97\%) containing $0.01 \%$ acetic acid at a flow rate of $4 \mathrm{~mL} / \mathrm{min}$. The detection was run at $260 \mathrm{~nm}$ with a diode array detector. Quantification was obtained using the peak areas with known amounts of $\mathrm{ABA}(5-50 \mathrm{ng} / \mathrm{ml})$ based on $\mathrm{Li}$ et al. [21].

The extraction and evaluation of polyamines were performed based on Walter and Geuns [22].

\section{Statistical analysis}

All experiments were conducted with three replicates, and the differences between treatments with different variables were tested by general linear model followed by Duncan test. Differences were considered as significant at $p<0.05$. To determine the best target for $\mathrm{PBZ}$ and $\mathrm{GA}_{3}$ and understand their roles under salinity, Principal component analysis (PCA) was applied, and the results were shown. Principal component analysis is a popular method to reduce a set of observations of possibly correlated variables into a set of principal components. In other words, each parameter in PCA analysis receives component score based on the quantified data which contain the same information but orthogonal to each other.

\section{Results}

\section{Growth parameters}

Increasing $\mathrm{NaCl}$ concentration negatively affected the fresh weight, dry weight, stem length, root length, and water content of sweet sorghum (Table 1). The results indicated that these characteristics were significantly altered by $\mathrm{GA}_{3}$ and PBZ treatments. As a general pattern, $\mathrm{GA}_{3}$ and PBZ treatments affected fresh weight, dry weight, stem length, and root length. The lengths of stem and roots as well as the fresh and dry weight of stems were significantly 


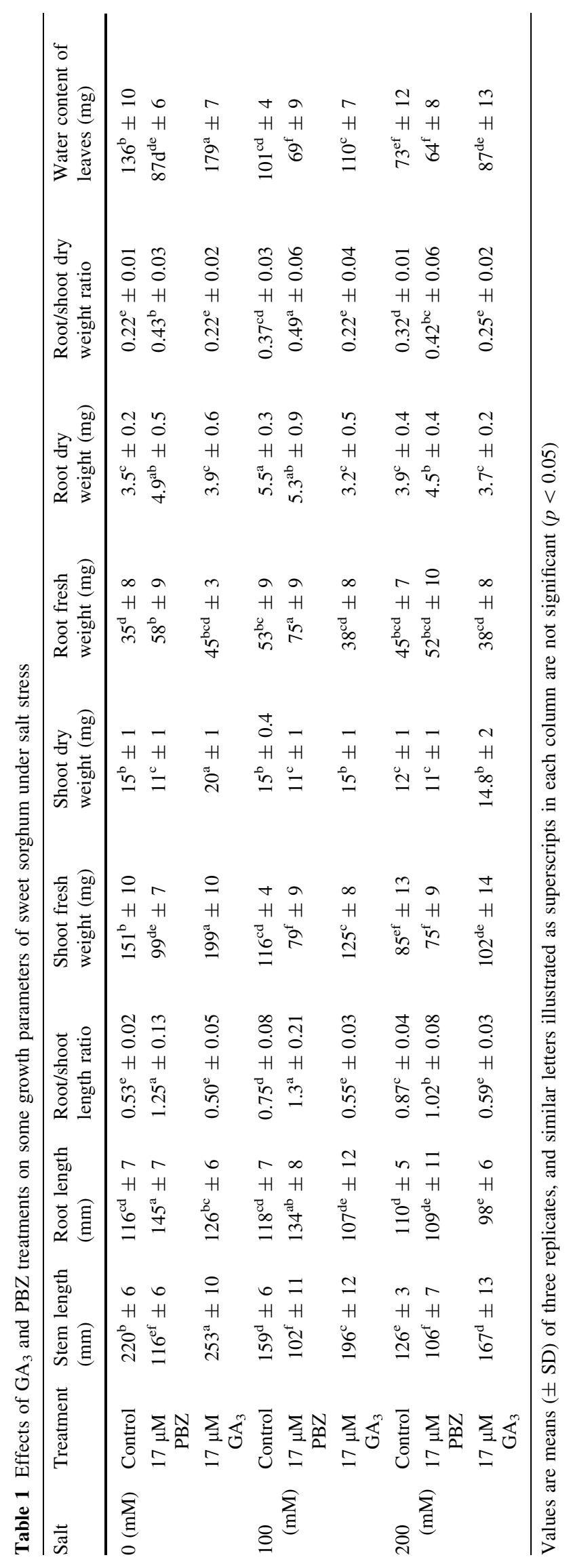


improved by $\mathrm{GA}_{3}$ application. However, the impact of $\mathrm{GA}_{3}$ was slightly reduced by increasing salinity in the medium. The stem length increased significantly by $\mathrm{GA}_{3}$ either with or without salt as compared with control (no PBZ) and PBZ treatments. Though PBZ treatments reduced stem length and fresh and dry weights of stem, these characteristics did not change significantly in the medium supplemented with salt. However, the root length and fresh and dry weights of roots were significantly increased by $\mathrm{PBZ}$, either with or without $\mathrm{NaCl}$, compared to $\mathrm{GA}_{3}$ treatments (Table 1). In our experiments, root/shoot length ratio and root/shoot dry weight ratio in sweet sorghum improved by increasing salinity. Looking at both ratios, it seemed $\mathrm{GA}_{3}$ has a more negative effect compared to PBZ. Under salinity, the water content (WC) of sweet sorghum decreased significantly by increasing salinity for both $\mathrm{GA}_{3}$ and PBZ treatments. Gibberellic acid increased $\mathrm{WC}$ in non-saline medium, but PBZ decreased it significantly compared to the control. Under salt stress, the reduction in $\mathrm{WC}$ in $\mathrm{GA}_{3}$-treated plants was higher than PBZ-treated plants. For instance, the water content of plants treated with $\mathrm{GA}_{3}$ and $\mathrm{PBZ}$ in $200 \mathrm{mM} \mathrm{NaCl}$ was reduced by $54 \%$ and $28 \%$, respectively, compared to plants grown in the medium without salt.

\section{Photosynthetic Pigments}

Our results indicated that chlorophyll $a$, chlorophyll $b$, the total chlorophyll as well as the carotenoid contents were increased significantly by higher salinity. Treated plants with PBZ and $\mathrm{GA}_{3}$ under $200 \mathrm{mM}$ salt increased total chlorophyll about 21 , and $43 \%$, respectively, compared with untreated plants. When $100 \mathrm{mM} \mathrm{NaCl}$ was added to the medium, chlorophyll content of plants treated with $\mathrm{GA}_{3}$ decreased compared to PBZ-treated plants either with or without salt. In contrast, PBZ improved chlorophyll and carotenoid contents in response to $100 \mathrm{mM}$ salt compared to the control and $\mathrm{GA}_{3}$ (Table 2).

\section{Water soluble carbohydrates}

The level of water soluble carbohydrates (WSC) in the leaves of sweet sorghum was enhanced by increasing salinity, especially in $200 \mathrm{mM} \mathrm{NaCl}$. Application of PBZ without salt improved WSC dramatically (around 100\%) compared to control. However, the impact of PBZ was reduced slightly by increasing salinity in the medium. The highest WSC content was recorded in the medium containing PBZ and $200 \mathrm{mM}$ salt, which was not significantly different from $\mathrm{GA}_{3}$-treated plants at $200 \mathrm{mM} \mathrm{NaCl}$ (Table 2).

\section{Polyamines}

The results of $\mathrm{GA}_{3}, \mathrm{PBZ}$, and salinity on endogenous concentration of putrescine (PUT) are shown in Fig. 1A. Using $\mathrm{GA}_{3}$ as a single (without salinity) treatment increased PUT content $70 \%$ more than untreated plants and $100 \%$ higher than PBZ treatment. The concentration of PUT in $\mathrm{GA}_{3}$-treated plants decreased markedly by salinity; down to $60 \%$ in $200 \mathrm{mM}$ salt. In contrast, PBZ as well as untreated plants with hormones increased PUT up to $100 \mathrm{mM} \mathrm{NaCl}$ and then decreased PUT to the lowest amount in $200 \mathrm{mM} \mathrm{NaCl}$ (Fig. 1A). Gibberellic acid and PBZ in combination with salt stress had different impact on spermidine content. The highest spermidine (SPD) content was observed in $\mathrm{GA}_{3}$ treated plants. However, when $\mathrm{NaCl}$ was added to the medium, plants responded differently. For instance, in $100 \mathrm{mM} \mathrm{NaCl}$ spermidine concentration decreased in plants irrespective of the treatment $\left(\mathrm{GA}_{3}\right.$, PBZ, or control), while in $200 \mathrm{mM} \mathrm{NaCl}$ spermidine concentration increased (Fig. 1B). The overall pattern of spermine (SPM) content is shown in Fig. 1C. In this study, under $100 \mathrm{mM}$ salt stress spermine content decreased, but it increased in $200 \mathrm{mM} \mathrm{NaCl}$ by PBZ. Salt stress without exogenous $\mathrm{PBZ}$ or $\mathrm{GA}_{3}$ application increased spermine only in $200 \mathrm{mM} \mathrm{NaCl}$. A similar pattern was observed when $\mathrm{GA}_{3}$ was used.

Because $\mathrm{GA}_{3}$ content was affected by $\mathrm{PBZ}$ and $\mathrm{GA}_{3}$ treatments, we were interested in knowing how and to what extend $\mathrm{GA}_{3}$ variation may affect polyamine content. Therefore, we calculated the ratio of total polyamine/ $\mathrm{GA}_{3}$ which showed that the total polyamine/GA $\mathrm{G}_{3}$ in PBZ-treated plants was higher than $\mathrm{GA}_{3}$ treated plants and untreated plants (control). This ratio was increased in 100 and $200 \mathrm{mM} \mathrm{NaCl}$ in PBZ and control plants, whereas in $\mathrm{GA}_{3}$ treated plants it was increased only in $200 \mathrm{mM} \mathrm{NaCl}$ (Fig. 1D).

\section{Phytohormones concentration}

To understand the interaction of treatments including $\mathrm{GA}_{3}$, $\mathrm{PBZ}$, and $\mathrm{NaCl}$, the endogenous concentrations of some key phytohormones were measured. As a general pattern, $\mathrm{GA}_{3}$ content in plants decreased by increasing salinity. Our results indicated that the level of $\mathrm{GA}_{3}$ content decreased significantly in 0,100 , and $200 \mathrm{mM} \mathrm{NaCl}$, either with or without $\mathrm{GA}_{3}$ or PBZ. Although, the plants treated by $\mathrm{GA}_{3}$ showed higher $\mathrm{GA}_{3}$ content than PBZ-treated plants, the reduction in $\mathrm{GA}_{3}$ content was higher in $\mathrm{GA}_{3}$-treated plants than PBZ in $200 \mathrm{mM} \mathrm{NaCl}$. Our results show that $\mathrm{GA}_{3}$ in $200 \mathrm{mM}$ salt reduced $\mathrm{GA}_{3}$ content by about $73 \%$, but PBZ reduced $\mathrm{GA}_{3}$ content by about $48 \%$ (Fig. 2A).

The level of indoleacetic acid (IAA) was much higher in $\mathrm{GA}_{3}$-treated plants compared to PBZ under salt stress 
Table 2 Effect of $\mathrm{GA}_{3}$ and PBZ on chlorophyll, carotenoid, and water soluble carbohydrate (WSC) of sweet sorghum under salinity

\begin{tabular}{|c|c|c|c|c|c|c|}
\hline Salt & Treatment & $\begin{array}{l}\text { chlorophyll } \\
a\left(\mathrm{mg} \mathrm{g}^{-1} \mathrm{FW}\right)\end{array}$ & $\begin{array}{l}\text { chlorophyll } \\
b\left(\mathrm{mg} \mathrm{g}^{-1} \mathrm{FW}\right)\end{array}$ & $\begin{array}{l}\text { Total chlorophyll } \\
\left(\mathrm{mg} \mathrm{g}^{-1} \mathrm{FW}\right)\end{array}$ & $\begin{array}{l}\text { Carotenoid } \\
\left(\mathrm{mg} \mathrm{g}^{-1} \mathrm{FW}\right)\end{array}$ & $\begin{array}{l}\text { Leaf WSC } \\
\left(\mathrm{mg} \mathrm{g}^{-1} \mathrm{DW}\right)\end{array}$ \\
\hline \multirow[t]{3}{*}{$0(\mathrm{mM})$} & Control & $1.27^{\mathrm{cd}} \pm 0.26$ & $0.42^{\mathrm{de}} \pm 0.07$ & $1.91^{\mathrm{cd}} \pm 0.1$ & $0.48^{\text {cde }} \pm 0.03$ & $13^{\mathrm{d}} \pm 2.5$ \\
\hline & $\begin{array}{r}17 \mu \mathrm{M} \\
\text { PBZ }\end{array}$ & $1.68^{\mathrm{bc}} \pm 0.16$ & $0.56^{\mathrm{bc}} \pm 0.03$ & $2.28^{\mathrm{bc}} \pm 0.2$ & $0.57^{\mathrm{bc}} \pm 0.03$ & $25^{\mathrm{abc}} \pm 2.5$ \\
\hline & $\begin{array}{r}17 \mu \mathrm{M} \\
\mathrm{GA}_{3}\end{array}$ & $1.13^{\mathrm{d}} \pm 0.20$ & $0.39^{\mathrm{e}} \pm 0.09$ & $1.55^{\mathrm{d}} \pm 0.3$ & $0.41^{\mathrm{e}} \pm 0.09$ & $14^{\mathrm{cd}} \pm 1.5$ \\
\hline \multirow{3}{*}{$\begin{array}{l}100 \\
\quad(\mathrm{mM})\end{array}$} & Control & $1.65^{\mathrm{bc}} \pm 0.01$ & $0.55^{\mathrm{bcd}} \pm 0.001$ & $2.23^{\mathrm{bc}} \pm 0.01$ & $0.53^{\mathrm{cd}} \pm 0.02$ & $20^{\mathrm{bcd}} \pm 0.2$ \\
\hline & $\begin{array}{r}17 \mu \mathrm{M} \\
\mathrm{PBZ}\end{array}$ & $2.15^{\mathrm{a}} \pm 0.16$ & $0.67^{\mathrm{ab}} \pm 0.06$ & $2.86^{\mathrm{a}} \pm 0.2$ & $0.67^{\mathrm{ab}} \pm 0.04$ & $31^{\mathrm{ab}} \pm 4.3$ \\
\hline & $\begin{array}{r}17 \mu \mathrm{M} \\
\mathrm{GA}_{3}\end{array}$ & $1.17^{\mathrm{d}} \pm 0.2$ & $0.26^{\mathrm{f}} \pm 0.08$ & $1.62^{\mathrm{d}} \pm 0.2$ & $0.44^{\mathrm{de}} \pm 0.04$ & $31^{\mathrm{ab}} \pm 3.4$ \\
\hline \multirow{3}{*}{$\begin{array}{l}200 \\
\quad(\mathrm{mM})\end{array}$} & Control & $1.97^{\mathrm{ab}} \pm 0.17$ & $0.59^{\mathrm{abc}} \pm 0.07$ & $2.63^{\mathrm{ab}} \pm 0.2$ & $0.72^{\mathrm{a}} \pm 0.1$ & $26^{\mathrm{ab}} \pm 3.3$ \\
\hline & $\begin{array}{r}17 \mu \mathrm{M} \\
\mathrm{PBZ}\end{array}$ & $2.06^{\mathrm{ab}} \pm 0.38$ & $0.7^{\mathrm{a}} \pm 0.01$ & $2.76^{\mathrm{ab}} \pm 0.5$ & $0.67^{\mathrm{ab}} \pm 0.08$ & $32^{\mathrm{a}} \pm 3.2$ \\
\hline & $\begin{array}{r}17 \mu \mathrm{M} \\
\mathrm{GA}_{3}\end{array}$ & $1.69^{\mathrm{bc}} \pm 0.3$ & $0.48^{\text {cde }} \pm 0.04$ & $2.21^{\mathrm{bc}} \pm 0.4$ & $0.56^{\mathrm{bc}} \pm 0.07$ & $31^{\mathrm{ab}} \pm 3.6$ \\
\hline
\end{tabular}

Values are means $( \pm \mathrm{SD})$ of three replicates, and similar letters illustrated as superscripts in each column are not significant $(p<0.05)$

Fig. 1 The effect of GA3 and PBZ treatments on leaf putrescine (A), spermidine $(\mathbf{B})$, spermine $(\mathbf{C})$, and total polyamines $/ \mathrm{GA}_{3}$ ratio $(\mathbf{D})$ of sweet sorghum under salinity. The values are means of three replicates, \pm standard error. Common letters are not significant $(p<0.05)$
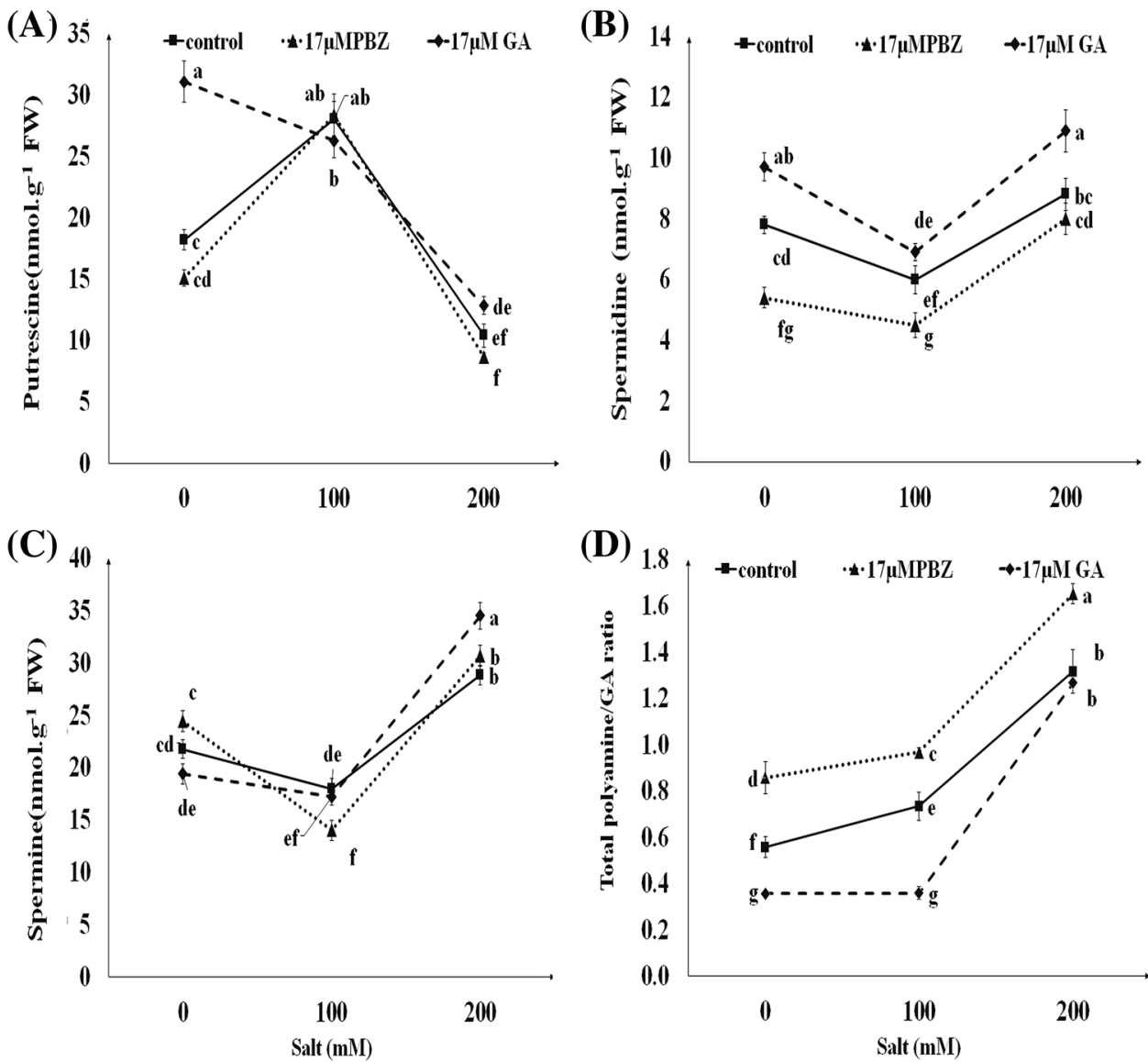

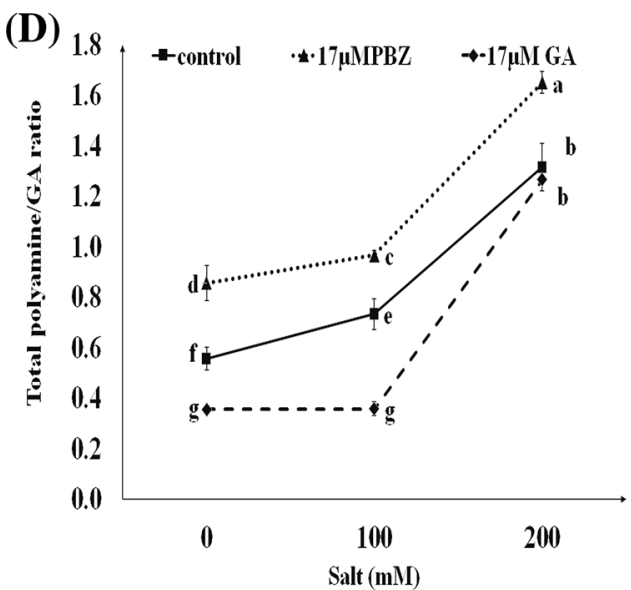

(Fig. 2B). The levels of IAA decreased in plants with or without $\mathrm{GA}_{3}$ and $\mathrm{PBZ}$ as concentration of $\mathrm{NaCl}$ increased in the medium. The amount of IAA in PBZ-treated plants was significantly lower than $\mathrm{GA}_{3}$-treated and -untreated plants. While large reduction in IAA concentration was 
Fig. 2 The effect of $\mathrm{GA}_{3}$ and PBZ on endogenous concentrations of leaf $\mathrm{GA}_{3}(\mathbf{A})$, IAA (B), zeatin (C), and ABA (D) in sweet sorghum under salinity. The values are means of three replicates, \pm standard error. Common letters are not significant $(p<0.05)$
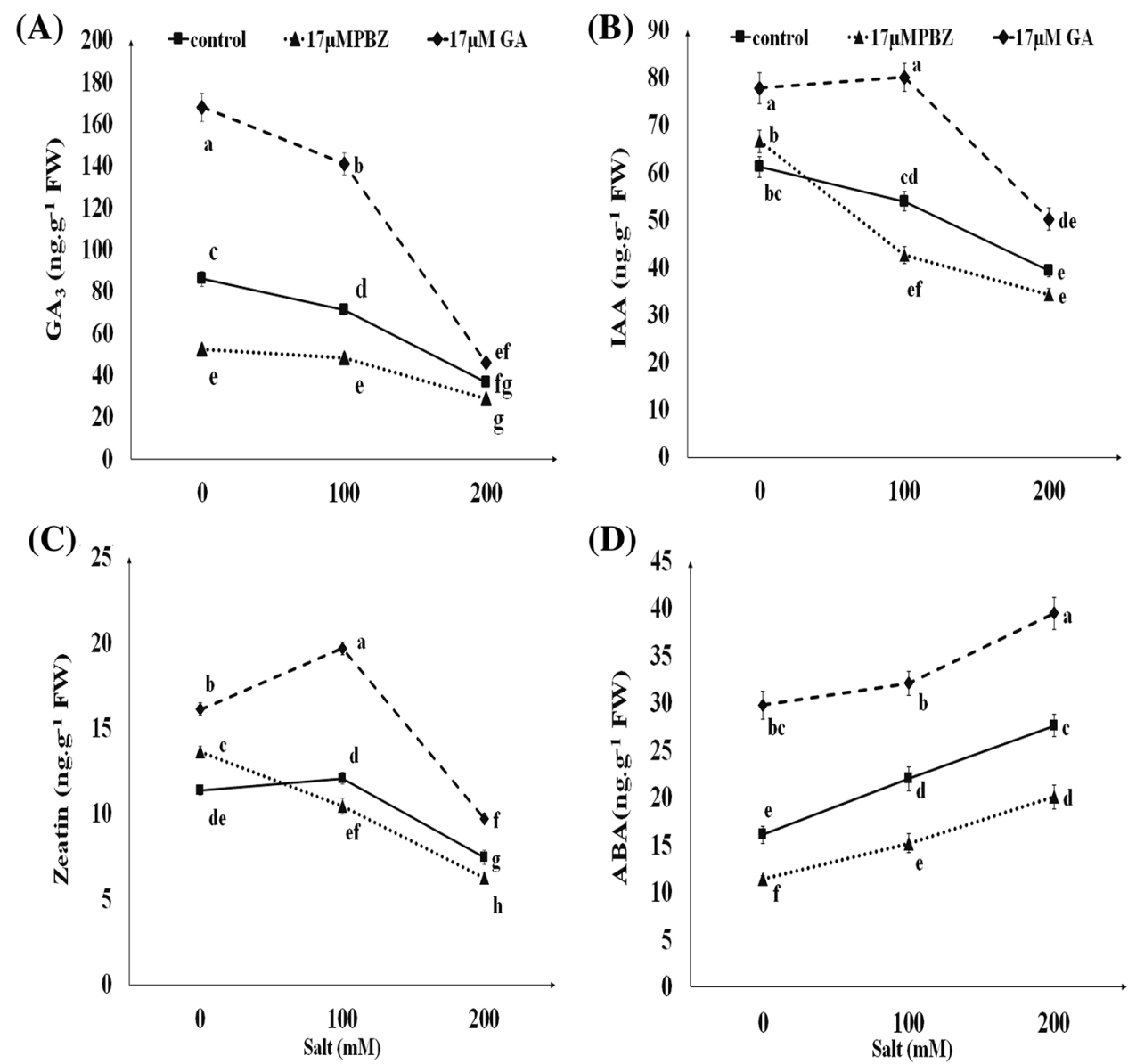

observed by $\mathrm{PBZ}, \mathrm{GA}_{3}$, and untreated plants at $200 \mathrm{mM}$ $\mathrm{NaCl}$, these differences were not significant (Fig. 2B).

In $\mathrm{GA}_{3}$-treated plants zeatin, concentration with or without $\mathrm{NaCl}$ application was the highest compared to untreated and PBZ-treated plants. Generally, zeatin content increased up to $100 \mathrm{mM} \mathrm{NaCl}$, but significantly declined when salt concentration increased to $200 \mathrm{mM} \mathrm{NaCl}$. Additionally, PBZ-treated plants had the lowest amount of zeatin, especially at $200 \mathrm{mM} \mathrm{NaCl}$ (Fig. 2C).

On the other hand, the concentration of ABA increased as the concentration of $\mathrm{NaCl}$ increased (Fig. 2D). The highest amount of $\mathrm{ABA}$ was observed in $\mathrm{GA}_{3}$-treated plants with $200 \mathrm{mM} \mathrm{NaCl}$.

To understand the role of different phytohormones in response to salt stress, we calculated their ratio to $\mathrm{GA}_{3}$. In this regard, the $\mathrm{ABA} / \mathrm{GA}_{3}$ ratio (Fig. 3A) increased sharply in $200 \mathrm{mM} \mathrm{NaCl}$ under $\mathrm{GA}_{3}$ or PBZ application. Interestingly, in severe salt stress $(200 \mathrm{mM})$, this ratio was much higher in $\mathrm{GA}_{3}$-treated plants than PBZ-treated ones.

The IAA/ $/ \mathrm{GA}_{3}$ ratio in $\mathrm{PBZ}$ treatments with or without salt was higher than control and $\mathrm{GA}_{3}$-treated plants. In $\mathrm{GA}_{3}$-treated or control plants, this ratio was high when plants were exposed to $200 \mathrm{mM}$ salt concentration. In PBZ-treated plants the IAA/GA $\mathrm{G}_{3}$ ratio declined under
$100 \mathrm{mM} \mathrm{NaCl}$ and then increased when the salt concentration was increased to $200 \mathrm{mM}$ (Fig. 3B).

Generally, the ratio of $\mathrm{CK}$ (in this case zeatin) to $\mathrm{GA}_{3}$ was the highest in PBZ-treated plants irrespective of whether or not the plants were exposed to salinity treatment. When $100 \mathrm{mM} \mathrm{NaCl}$ was added to the medium, this ratio decreased slightly and remained constant in $200 \mathrm{mM}$ salt concentration. In contrast, $\mathrm{GA}_{3}$ treatment in response to salinity increased the $\mathrm{CK} / \mathrm{GA}_{3}$ ratio slightly (Fig. $3 \mathrm{C}$ ).

\section{Identification of $\mathrm{NaCl}, \mathrm{GA}_{3}$, and $\mathrm{PBZ}$ objectives}

To identify the best objectives for salinity, $\mathrm{GA}_{3}$ and PBZ in sweet sorghum, principal component analysis (PCA) was carried out. The principal components 1 and 2 (PCA1 and PCA2, respectively) obtained from the growth parameters as well as physiological and phytohormones parameters subjected to salinity are shown in Fig. 4A. Gibberellic acid and PBZ, as PCA1, described $61.1 \%$ and PCA2 described $20.5 \%$ (the sum equals to $81.6 \%$ ) of all measured parameters. In fact, PCA visualized the main objectives of $\mathrm{GA}_{3}$ and PBZ on sweet sorghum, under salt stress (Fig. 4A, B).

The PCA results (Fig. 4) clearly indicated that growth parameters, that is physiological and phytohormones in this 

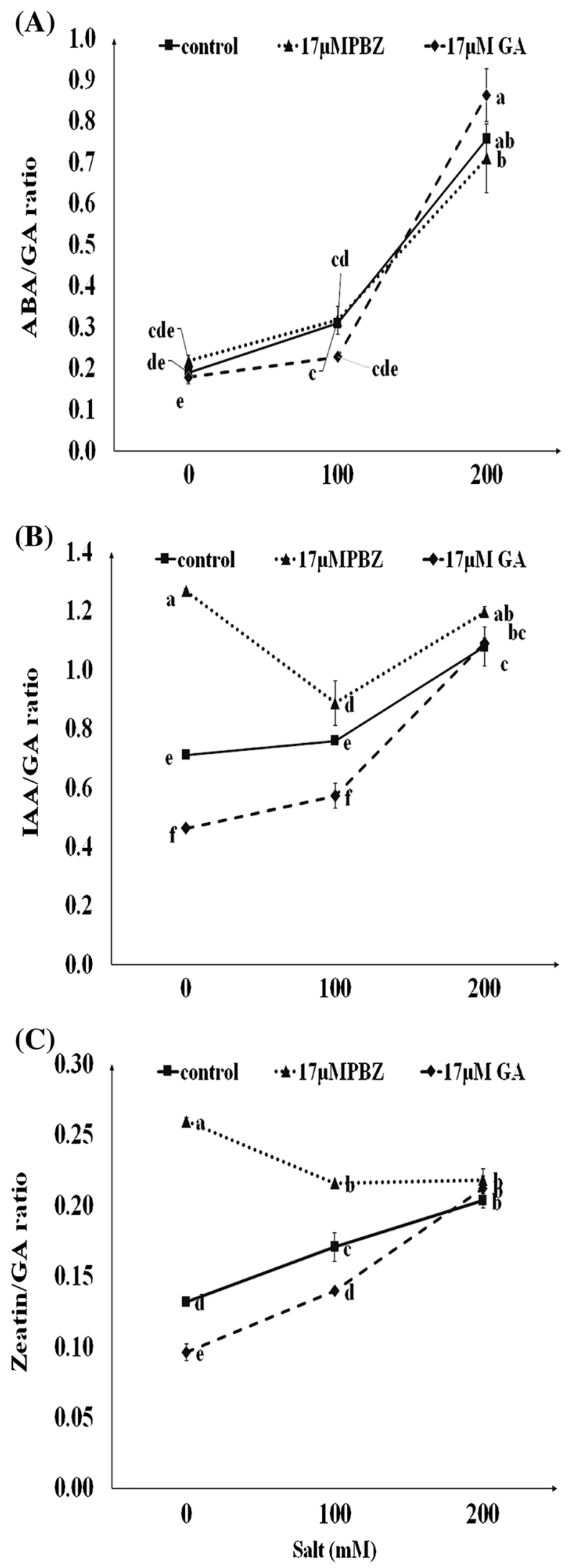

4Fig. 3 The effect of $\mathrm{GA}_{3}$ and $\mathrm{PBZ}$ treatments on $\mathrm{ABA} / \mathrm{GA}_{3}(\mathbf{A})$, IAA/GA $(\mathbf{B})$, and zeatin/ $/ \mathrm{GA}_{3}(\mathbf{C})$ ratios, in leaves of sweet sorghum under salinity. The values are means of three replicates, \pm standard error. Common letters are not significant $(p<0.05)$

study, might be divided into three separate groups. Root length was a group associated with PBZ treatment (Fig. 4A). Whereas, root/shoot length, root/shoot dry weight, root fresh and dry weights, total chlorophyll, carotenoids, WSC, $\mathrm{CK} / \mathrm{GA}_{3}$, and $\mathrm{IAA} / \mathrm{GA}_{3}$ consisted a group linked with $\mathrm{NaCl}$ and $\mathrm{PBZ}+$ salt (Fig. 4A). Finally, auxin, cytokinin, PUT, SPD, ABA, water content (WC), shoot dry and fresh weights, and shoot length were found on the left side of the biplot strongly related to $\mathrm{GA}_{3}$ (Fig. 4A). Figure 4B summarizes a simple illustration of the main objectives of the above-mentioned characteristics for $\mathrm{GA}_{3}$ and PBZ under salinity. We found that the SPM, polyamines/GA 3 , and $\mathrm{ABA} / \mathrm{GA}_{3}$ were the main objectives of salinity regulating total chlorophyll, carotenoid, and WS contents in sweet sorghum. In conclusion, the main objectives of $\mathrm{PBZ}$ under salinity were $\mathrm{ABA} / \mathrm{GA}_{3}, \mathrm{CK} / \mathrm{GA}_{3}$, and IAA/GA 3 , while the levels of SPD, ABA, and ABA/ $\mathrm{GA}_{3}$ were the main objectives of $\mathrm{GA}_{3}$ under salinity (Fig. 4B).

\section{Discussion}

As a general response to salt stress, plant growth is affected negatively by a variety of physiological changes, such as osmotic shock, ion toxicity, and nutritional imbalance [23]. This study showed that, although stem length, fresh and dry weight, and water content decreased the adverse effect of $\mathrm{NaCl}$ by $\mathrm{GA}_{3}$ treatment, the impact of $\mathrm{GA}_{3}$ was reduced slightly with rising salt level. It has been known that, $\mathrm{GA}_{3}$ enhances plant growth by promoting cell division and elongation [24] under salinity, for instance in arabidopsis [25], wheat [26], and rice [8]. We found that application of $\mathrm{GA}_{3}$ increased the levels of $\mathrm{CK}$ and IAA in leaves, perhaps due to the beneficial effects of hormonal homeostasis of $\mathrm{GA}_{3}$ and its ion uptake and possibly the photosynthesis process in the salt-stressed plants [8]. Salt stress may reduce carbon movement to shoot [27], yet increase carbon transferring to roots. This will consequently increase the root/shoot ratio, which might be an adaptive response [8]. Previously, it was indicated that the root/shoot ratio was increased in PBZ-treated seedling of rice [28] and the adverse effect was observed by $\mathrm{GA}_{3}$ [28]. We observed that, PBZ increased root length and subsequently resulted in improved water content under salt stress. The level of CK in sorghum was decreased in PBZ-treated plant. Interestingly, PCA showed that the root/shoot length ratio 
Fig. 4 Result of biplot Principal Components 1 and 2 analysis obtained from phytohormones and physiological parameters in sweet sorghum subjected to PBZ, salinity, $\mathrm{GA}_{3}(\mathbf{A})$, and the main objectives $(\mathbf{B})$

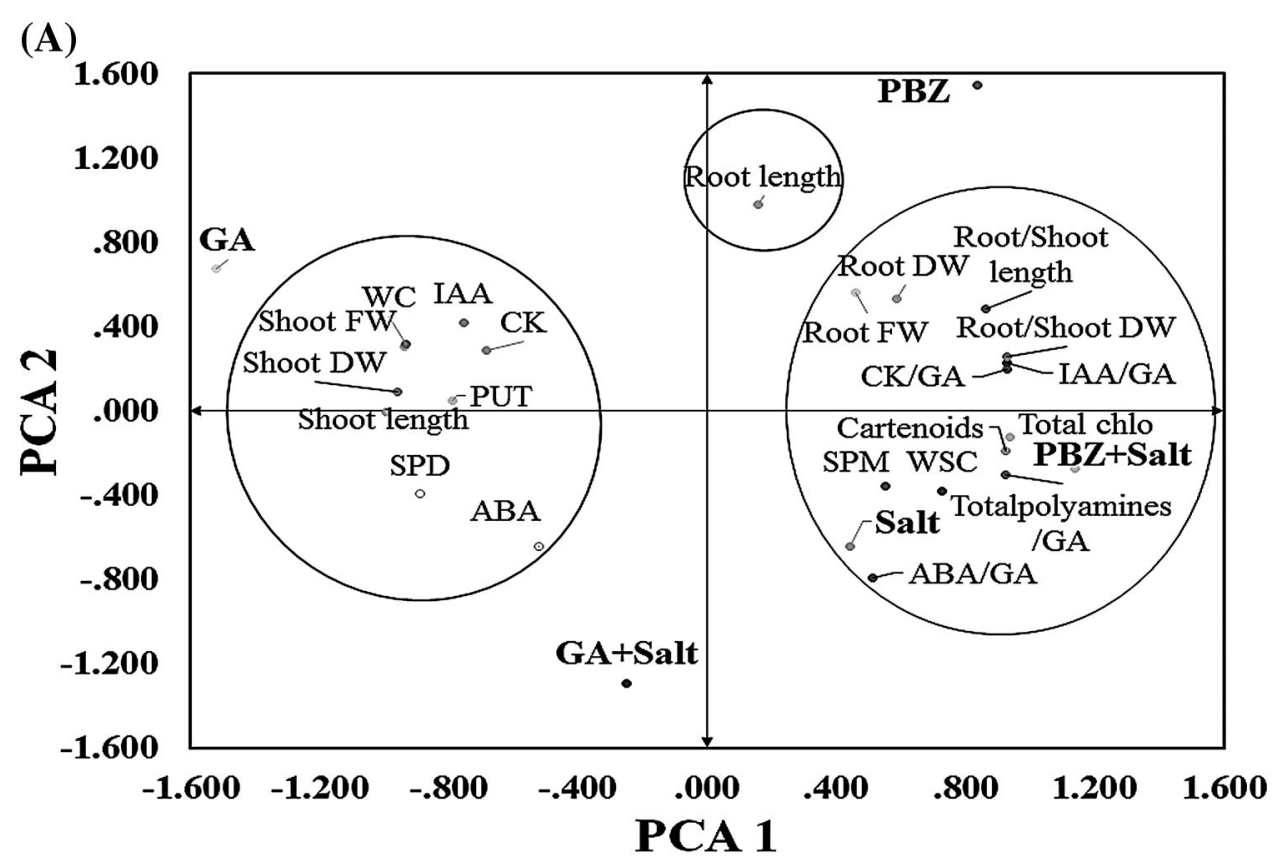

(B)

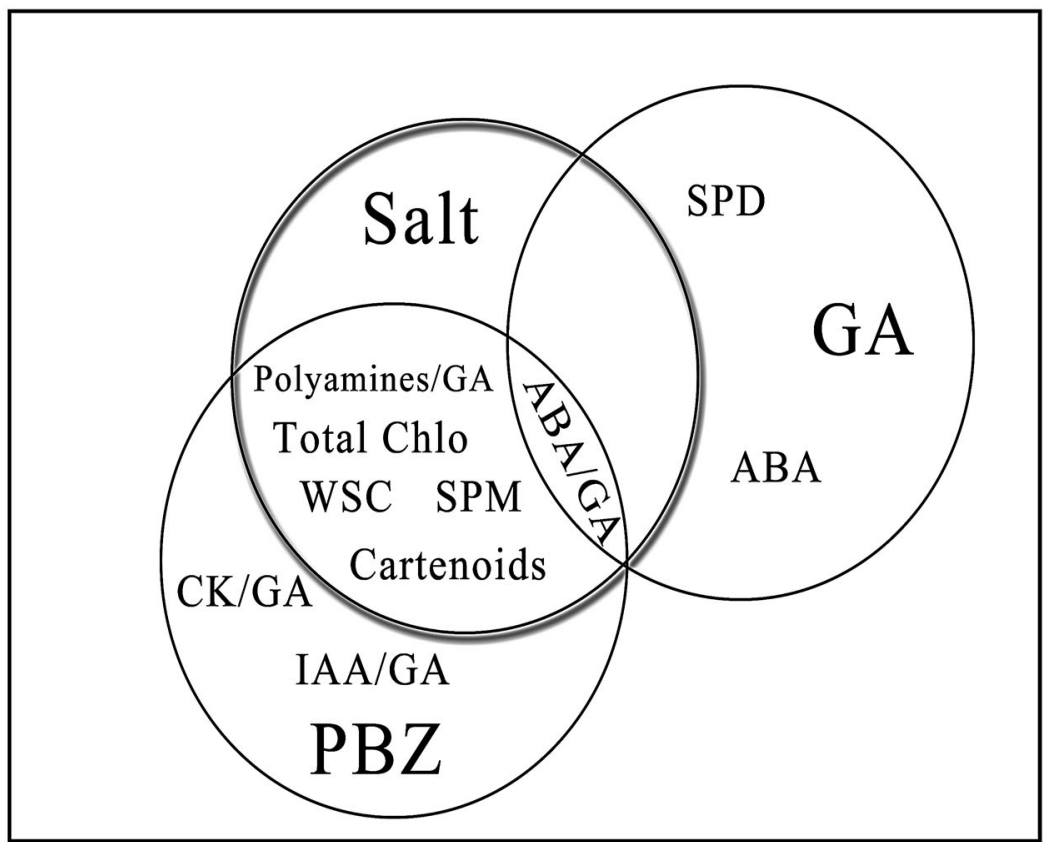

was positively correlated with $\mathrm{CK} / \mathrm{GA}_{3}$ and IAA/GA ratios. In our study, shoot fresh weight of sorghum was correlated with changes in plant height as reported by Yim et al. [28]. However, we showed that shoot fresh weight was negatively associated with total polyamines/GA 3 ratio. Moreover, various studies have shown that high polyamines level enhances cell division, root initiation, and early growth [29]. Therefore, altered level of $\mathrm{GA}_{3}$ resulting from PBZ and $\mathrm{GA}_{3}$ treatment in sorghum plants leads to different allocation patterns. Consequently, it seems that, root/ shoot ratio is regulated by $\mathrm{CK} / \mathrm{GA}_{3}, \mathrm{IAA} / \mathrm{GA}_{3}$, and total polyamines $/ \mathrm{GA}_{3}$ ratios.

Abiotic stress normally changes phytohormones level and photosynthesis process. It has been reported that chlorophyll content is decreased in salt susceptible plants such as tomato and pea [30], but it is increased or unchanged in relatively salt tolerant plants such as pearl millet, sugar beet, and cabbage [31]. Our data indicated that chlorophyll and carotenoid contents were increased significantly with salinity. This finding might be due to the nature of sorghum variety used in this study, which is a 
relatively salt tolerant sweet sorghum cultivar Sofra. However, the chlorophyll content in leaves of some varieties of sorghum reduced as a result of higher $\mathrm{NaCl}$ levels [32], indicating a genotype dependent response of sorghum cultivars to salinity [33]. It should be kept in mind that, chlorophyll content as a photosynthesis response of sorghum is also dependent on $\mathrm{NaCl}$ concentration. The positive effect of PBZ on chlorophyll accumulation was reported in some plant species [34], and a similar observation was seen in our study. This finding might be either due to decrease in leaf area by PBZ and condensation of chlorophyll [35] or increase in cytokinin levels in leaves [13]. In contrast, the decrease in chlorophyll resulted by $\mathrm{GA}_{3}$ treatment might be due to the expansion of the leaves and dilution of chlorophyll [36]. It has also been shown that polyamines are involved in the delayed loss of chlorophyll [37]. Furthermore, the result of PCA analysis indicated that, the total chlorophyll and carotenoids contents were strongly correlated with the total polyamines/ $\mathrm{GA}_{3}$ ratio in sweet sorghum. Since the total amount of polyamines/GA ratio was significantly enhanced by $\mathrm{PBZ}$ and salinity, it might be concluded that PBZ and salinity regulated chlorophyll and carotenoid accumulation by total polyamines $/ \mathrm{GA}_{3}$ ratio.

Some variations have been reported in soluble carbohydrates content in response to salinity in different varieties of sorghum [3, 38, 39]. For instance, salinity decreased the amount of glucose and fructose in sorghum cv. Keller, while increased them in cv. Sofra [38]. In this study, WSC was increased in response to salinity, but PBZ was effective only under non-salinity condition. In wheat, however, PBZ increased WSC in the leaves under salinity. On the other hand, in sorghum plants treated with salinity supplemented with either $\mathrm{GA}_{3}$ or PBZ, WSC content correlated positively with the total amount of polyamines $/ \mathrm{GA}_{3}$ and $\mathrm{ABA} / \mathrm{GA}_{3}$ ratios. Interestingly, $\mathrm{ABA} / \mathrm{GA}_{3}$ is a common target of $\mathrm{GA}_{3}$ and PBZ under salinity. Additionally, the increase in the total polyamines/ $\mathrm{GA}_{3}$ ratio led to improved chlorophyll content and consequently resulted in an increase in WSC in sorghum plants treated with PBZ.

Our results indicated that putrescine (PUT) levels decreased, while spermine (SPM) levels increased by salinity. Accumulation of SPM by raising salinity was reported by Maiale et al. [10] in rice. Chai et al. [40] provided strong evidence indicating that SPM improved growth of sweet sorghum under salinity. It can be suggested that SPM may act as a compatible solute, like proline, for homeostasis of the cells under $\mathrm{NaCl}$ treatment. Iqbal and Ashraf [26] reported that $\mathrm{GA}_{3}$ affects plant ability to synthesize polyamines based on the concentration of $\mathrm{GA}_{3}$ under salinity. Triazole compounds, including PBZ, reduce ethylene formation by blocking amino cyclopropane carboxylic acid (ACC) oxidase leading to an increase in polyamines level [13]. Low levels of putrescine detected in our study might be linked to the ABA biosynthesis and the inhibition of gibberellic acid biosynthesis [41]. Furthermore, accumulation of SPD in sweet sorghum is linked with $\mathrm{ABA}$ and is negatively correlated with IAA/GA 3 and $\mathrm{CK} / \mathrm{GA}_{3}$ ratios. Therefore, it seems that the reduction in $\mathrm{GA}_{3}$ levels by $\mathrm{PBZ}$ together with the $\mathrm{GA}_{3}$ addition to the medium regulates PUT concentration under salinity [26]. Seemingly, the alternation of PUT content might be modulated by ABA, IAA/GA, and CK/GA levels in sweet sorghum.

Application of paclobutrazol reduced $\mathrm{GA}_{3}$ content in sorghum plants, possibly via the inhibition of monooxygenases that catalyze oxidative steps from ent-kaurene to ent-kaurenoic [13]. Accumulation of DELLA protein in GA signaling pathway or GA degradation in arabidopsis plants might be other reasons for sorghum plants lack of response to $\mathrm{GA}_{3}$ as reported [24]. Interestingly, an increased level of DELLA expression was observed when sorghum treated with exogenous PBZ [42]. Therefore, the difference in sorghum plants response to $\mathrm{GA}_{3}$ and $\mathrm{PBZ}$ treatments under salinity might be related to hormonal hemostasis, $\mathrm{GA}_{3}$ metabolism, and the stability of DELLA proteins.

It was reported that auxin influences GA biosynthesis and interacts positively with GA in plant signaling [7]. For instance, increasing $\mathrm{GA}_{3}$ levels leads to significant increase in IAA content [43]. This effect may be due to either increased IAA biosynthesis or increase in auxin transport from apical meristem. Björklund et al. [43] showed that, increasing IAA content in Populus sp. treated with $\mathrm{GA}_{3}$ was correlated with auxin transport from apical meristem. Also, it is shown that the application of $\mathrm{GA}_{3}$ during salt stress in rice improves auxin content, which is similar to our findings [44]. There is conflicting reports on PBZ interaction with auxin in plants under stress conditions. Some reports indicated that triazoles such as PBZ have no significant impact on auxin levels [13], but other investigations have reported that the IAA levels reduced by PBZ under abiotic stress [45]. In the present study, severe salinity dramatically reduced IAA, CK, and some polyamines levels in sorghum, as was reported by Björklund et al. [43] and Shao et al. [46] in other plant species. Salinity increased IAA/ $\mathrm{GA}_{3}$ ratio, which was also markedly increased by PBZ, a $\mathrm{GA}_{3}$ antagonist. Björklund et al. [43] suggested that IAA/ $\mathrm{GA}_{3}$ ratio is established by complex cross-talk and self-control mechanisms and possibly by the expression of genes involved in auxin transport and $\mathrm{GA}_{3}$ metabolism.

Since $\mathrm{GA}_{3}$ can induce salt tolerance in plants by increasing CK and IAA, it seems that sorghum is able to survive under salinity with less damage through changes to $\mathrm{CK}$ and IAA levels. Moreover, triazole compounds can 
stimulate CK accumulation [13]. We found that the root/ shoot ratio in PBZ-treated sorghum increased in response to $\mathrm{NaCl}$. The decrease in $\mathrm{CK}$ content under salt stress might be due to the movement of $\mathrm{CK}$ from roots to shoots.

$\mathrm{ABA}$ has a critical role in abiotic and biotic stress and is a key hormone in response to salinity stress [47]. The detected trend of ABA accumulation under salinity in this study was consistent with many other works showing that either an improved ABA biosynthesis or an enhanced translocation from the roots to the shoots may happen, after a particular stress threshold, in response to salinity [48]. The antagonistic roles between $\mathrm{ABA}$ and $\mathrm{GA}_{3}$ are presumed for numerous plant developmental processes such as germination and flowering [7]. However, there are conflicting data about the effect of $\mathrm{GA}_{3}$ on ABA level. Although pretreatments of wheat seeds with $\mathrm{GA}_{3}$ reduced ABA accumulation in response to seawater [49], Iqbal and Ashraf [26] reported that $\mathrm{GA}_{3}$ improved the levels of free ABA in leaves in salt tolerant wheat cultivars, while reverse trends were observed for the salt intolerant cultivars. The PCA results indicated that $\mathrm{ABA} / \mathrm{GA}_{3}$ was a common target of $\mathrm{GA}_{3}$ and $\mathrm{PBZ}$ under salinity. Therefore, the $\mathrm{ABA} / \mathrm{GA}_{3}$ ratio plays a pivotal role in response to salinity, explaining the levels of $\mathrm{ABA}$ in $\mathrm{GA}_{3}$ and $\mathrm{PBZ}$ treatments.

Finally, our findings indicate that $\mathrm{GA}_{3}$ can reduce the negative effects of salt by increasing some phytohormones in moderate salt stress. However, the main objectives of $\mathrm{GA}_{3}$ under salinity were ABA and SPD contents as well as $\mathrm{ABA} / \mathrm{GA}_{3}$ ratio. Though $\mathrm{GA}_{3}$ and $\mathrm{PBZ}$ have different roles against salt stress, $\mathrm{ABA} / \mathrm{GA}_{3}$ ratio was a similar target of $\mathrm{GA}_{3}$ and PBZ. This study suggests that altered levels of $\mathrm{GA}_{3}$ resulting from PBZ- and $\mathrm{GA}_{3}$-treated plants cause different allocation patterns in sweet sorghum by regulation of $\mathrm{CK} / \mathrm{GA}_{3}$, IAA/GA 3 , and total polyamines/GA ratio. Also, accumulation of chlorophyll pigments, carotenoids, and water soluble carbohydrates in sorghum plants under salinity, that is regulated by the total polyamines $/ \mathrm{GA}_{3}$ and $\mathrm{ABA} / \mathrm{GA}_{3}$ ratios, is positively correlated with $\mathrm{PBZ}$ application.

Acknowledgments Authors thank University of Isfahan and University of Payame Noor for their support. The authors are grateful to Dr Mahmoud-Reza Hemami for statistical analysis and Professor Acram Taji and Dr Mehdi Layeghifard for their critical review of the manuscript. Support of Plant Antioxidants Center of Excellence in University of Isfahan is gratefully acknowledged.

\section{References}

1. Horie T, Karahara I, Katsuhara M (2012) Salinity tolerance mechanisms in glycophytes: an overview with the central focus on rice plants. Rice 5:11
2. Ji H, Pardo JM, Batelli G, Van Oosten MJ, Bressan RA, Li X (2013) The Salt Overly Sensitive (SOS) pathway: established and emerging roles. Mol Plant 6:275-286

3. Tari I, Laskay G, Takacs Z, Poor P (2013) Response of Sorghum to abiotic stresses: a review. J Agron Crop Sci 199:264-274

4. Kafi M, Shariat Jafari M, Moayedi A (2013) The sensitivity of grain Sorghum (Sorghum bicolor L.) developmental stages to salinity stress: an integrated approach. J Agric Sci Technol 15:723-736

5. Netondo GW, Onyango JC, Beck E (2004) Sorghum and salinity: I. Response of growth, water relations, and ion accumulation to $\mathrm{NaCl}$ salinity. Crop Sci 44:797

6. Ngara R, Ndimba R, Borch-Jensen J, Jensen ON, Ndimba B (2012) Identification and profiling of salinity stress-responsive proteins in Sorghum bicolor seedlings. J Proteomics 75:4139-4150

7. Weiss D, Ori N (2007) Mechanisms of cross talk between gibberellin and other hormones. Plant Physiol 144:1240-1246

8. Khan NA, Nazar R, Iqbal N, Anjum NA (2012) Phytohormones and abiotic stress tolerance in plants. Springer, Berlin

9. Javid MG, Sorooshzadeh A, Moradi F, Sanavy SAMM, Allahdadi I (2011) The role of phytohormones in alleviating salt stress in crop plants. AJCS 5:726

10. Maiale S, Sánchez DH, Guirado A, Vidal A, Ruiz OA (2004) Spermine accumulation under salt stress. J Plant Physiol 161:35-42

11. Fletcher R, Gilley A, Sankhla N, Davis TD (1999) Triazoles as plant growth regulators and stress protectants. Hortic Rev 24:55-138

12. Jaleel CA, Gopi R, Manivannan P, Kishorekumar A, Gomathinayagam M, Vam RP (2007) Changes in biochemical constituents and induction of early sprouting by triadimefon treatment in white yam (Dioscorea rotundata Poir.) tubers during storage. J Zhejiang Univ Sci B 8:283-288

13. Rademacher W (2000) Growth retardants: effects on gibberellin biosynthesis and other metabolic pathways. Annu Rev Plant Biol 51:501-531

14. Hoagland DR, Arnon DI (1950) The water-culture method for growing plants without soil. Circ Calif Agric Exp Sta 347:1-32

15. Lichtenthaler HK, Wellburn AR (1983) Determinations of total carotenoids and chlorophylls $a$ and $b$ of leaf extracts in different solvents. Biochem Soc Trans 11:591-592

16. Dubois M, Gilles KA, Hamilton JK, Rebers P, Smith F (1956) Colorimetric method for determination of sugars and related substances. Anal Chem 28:350-356

17. Ma Z, Ge L, Lee AS, Yong JWH, Tan SN, Ong ES (2008) Simultaneous analysis of different classes of phytohormones in coconut (Cocos nucifera L.) water using high-performance liquid chromatography and liquid chromatography-tandem mass spectrometry after solid-phase extraction. Anal Chim Acta 610:274-281

18. Shindy WW, Smith OE (1975) Identification of plant hormones from cotton ovules. Plant Physiol 55:550-554

19. Tang Y, Wang L, Ma C, Liu J, Liu B, Li H (2011) The use of HPLC in determination of endogenous hormones in anthers of bitter melon. J Life Sci 5:139-142

20. Ge L, Yong JWH, Tan SN, Yang XH, Ong ES (2004) Analysis of some cytokinins in coconut (Cocos nucifera L.) water by micellar electrokinetic capillary chromatography after solid-phase extraction. J Chromatogr 1048:119-126

21. Li X-J, Yang M-F, Chen H, Qu L-Q, Chen F, Shen S-H (2010) Abscisic acid pretreatment enhances salt tolerance of rice seedlings: proteomic evidence. Biochimica et Biophysica Acta (BBA)-Proteins and Proteomics 1804:929-940

22. Walter HJ-P, Geuns JM (1987) High speed HPLC analysis of polyamines in plant tissues. Plant Physiol 83:232-234 
23. Flowers T, Hajibagherp M, Yeo A (1991) Ion accumulation in the cell walls of rice plants growing under saline conditions: evidence for the Oertli hypothesis. Plant Cell Environ 14:319-325

24. Colebrook EH, Thomas SG, Phillips AL, Hedden P (2014) The role of gibberellin signalling in plant responses to abiotic stress. J Exp Biol 217:67-75

25. Fahad S, Hussain S, Matloob A, Khan FA, Khaliq A, Saud S, Hassan S, Shan D, Khan F, Ullah N (2015) Phytohormones and plant responses to salinity stress: a review. Plant Growth Regul 75:391-404

26. Iqbal M, Ashraf M (2013) Gibberellic acid mediated induction of salt tolerance in wheat plants: growth, ionic partitioning, photosynthesis, yield and hormonal homeostasis. Environ Exp Bot 86:76-85. https://doi.org/10.1016/j.envexpbot.2010.06.002

27. de Lacerda CF, Cambraia J, Oliva MA, Ruiz HA (2005) Changes in growth and in solute concentrations in sorghum leaves and roots during salt stress recovery. Environ Exp Bot 54:69-76

28. Yim K-O, Kwon Y, Bayer D (1997) Growth responses and allocation of assimilates of rice seedlings by paclobutrazol and gibberellin treatment. J Plant Growth Regul 16:35-41

29. Bais HP, Ravishankar G (2002) Role of polyamines in the ontogeny of plants and their biotechnological applications. Plant Cell Tiss Org Cult 69:1-34

30. Lapina L, Popov B (1970) The effect of sodium chloride on the photosynthetic apparatus of tomatoes. Russ J Plant Physl 17:580-584

31. Jamil M, Rehman S, Rha E (2007) Salinity effect on plant growth, PSII photochemistry and chlorophyll content in sugar beet (Beta Vulgaris L.) and cabbage (Brassica Oleracea Capitata L.). Pakistan J Bot 39:753-760

32. Nawaz K, Talat A, Hussain K, Majeed A (2010) Induction of salt tolerance in two cultivars of sorghum (Sorghum bicolor L.) by exogenous application of proline at seedling stage. WASJ 10:93-99

33. Sun L, Zhou Y, Li F, Xiao M, Tao Y, Xu W, Huang R (2012) Impacts of salt stress on characteristics of photosynthesis and chlorophyll fluorescence of sorghum seedlings. Sci Agric Sinica 45:3265-3272

34. Sharma DK, Dubey A, Srivastav M, Singh A, Sairam R, Pandey R, Dahuja A, Kaur C (2011) Effect of putrescine and paclobutrazol on growth, physiochemical parameters, and nutrient acquisition of salt-sensitive citrus rootstock Karna khatta (Citrus karna Raf.) under $\mathrm{NaCl}$ stress. J Plant Growth Regul 30:301-311

35. Misra A, Sahu S, Misra M, Singh P, Meera I, Das N, Kar M, Sahu $P$ (1997) Sodium chloride induced changes in leaf growth, and pigment and protein contents in two rice cultivars. Biol Plant 39:257-262

36. Abbaspour J, Ehsanpour AA, Amini F (2012) The role of Gibberellic acid on some physiological responses of transgenic tobacco (Nicotiana tabacum L.) plant carrying Ri T-DNA. JCMR 3:75-80

37. Shu S, Guo S-R, Yuan L-Y (2012) A review: polyamines and photosynthesis advances in photosynthesis-fundamental aspects. In Mohammad Najafpour (ed) Tech. p 439-464

38. Almodares A, Hadi M, Ahmadpour H (2008) Sorghum stem yield and soluble carbohydrates under different salinity levels. Afr J Biotechnol 7:4051-4055

39. de Lacerda CF, Cambraia J, Oliva MA, Ruiz HA, Prisco JT (2003) Solute accumulation and distribution during shoot and leaf development in two sorghum genotypes under salt stress. Environ Exp Bot 49:107-120

40. Chai Y, Jiang C, Shi L, Shi T, Gu W (2010) Effects of exogenous spermine on sweet sorghum during germination under salinity. Biol Plant 54:145-148

41. Anwar R, Mattoo AK, Handa AK (2015) Polyamine interactions with plant hormones: crosstalk at several levels. In: Kusano T, Suzuki H (eds) Polyamines: a universal molecular nexus for growth, survival, and specialized metabolism. Springer, Berlin, p 267-302

42. Gao S, Xie X, Yang S, Chen Z, Wang X (2012) The changes of GA level and signaling are involved in the regulation of mesocotyl elongation during blue light mediated de-etiolation in Sorghum bicolor. Mol Biol Rep 39:4091-4100

43. Björklund S, Antti H, Uddestrand I, Moritz T, Sundberg B (2007) Cross-talk between gibberellin and auxin in development of Populus wood: gibberellin stimulates polar auxin transport and has a common transcriptome with auxin. Plant J 52:499-511

44. Kaya C, Tuna A, Yokaş I (2009) The role of plant hormones in plants under salinity stress. In: Ashraf M, Ozturk M, Athar H (eds) Salinity and water stress. Springer, Berlin, p 45-50

45. Aly AA, Latif HH (2011) Differential effects of paclobutrazol on water stress alleviation through electrolyte leakage, phytohormones, reduced glutathione and lipid peroxidation in some wheat genotypes (Triticum aestivum L.) grown in vitro. Rom Biotech Lett 6:6710-6721

46. Shao T, Li L, Wu Y, Chen M, Long X, Shao H, Liu Z, Rengel Z (2016) Balance between salt stress and endogenous hormones influence dry matter accumulation in Jerusalem artichoke. Sci Total Environ 568:891-898

47. Tran L-SP, Pal S (2014) Phytohormones: a window to metabolism, signaling and biotechnological applications. Springer, Berlin

48. Maggio A, Barbieri G, Raimondi G, De Pascale S (2010) Contrasting effects of GA3 treatments on tomato plants exposed to increasing salinity. J Plant Growth Regul 29:63-72

49. Aldesuquy H, Ibrahim A (2001) Interactive effect of seawater and growth bioregulators on water relations, abscisic acid concentration and yield of wheat plants. J Agron Crop Sci 187:185-193 